\title{
Real-Time, Optical Measurement of Gas Temperature and Particle Emissivity in a Full-Scale Steelmaking Furnace
}

\author{
SALVADOR REGO-BARCENA, REZA MANI, FUT YANG, REBECCA SAARI, \\ and MURRAY J. THOMSON
}

\begin{abstract}
This article summarizes the successful implementation of a novel technique for measuring gas temperature and particle emissivity in real time at the mouth of a full-scale basic oxygen furnace (BOF). Both the technique and the data presented here may be useful to both process-control professionals interested in energy balances and computational fluid dynamic (CFD) modelers seeking in-situ data for their specific radiation heat-transfer submodels and temperatureboundary conditions. A description of the sensor, the retrieval algorithms, and the assumptions associated with each is included. The technique is based on midinfrared-emission spectroscopy. Results from a campaign spanning seven heats at a 168-tonne converter with data points every 2 seconds have been reported. During decarburization, the average off-gas temperature and particle emissivity were $1471 \mathrm{~K}$ and 0.55 , respectively, for low-carbon heats (aim carbon $<0.08 \mathrm{pct}$ ), and $1517 \mathrm{~K}$ and 0.36 , respectively, for high-carbon heats (aim carbon $>0.30 \mathrm{pct}$ ). Practical issues, validation of the assumptions, and measurement uncertainty are discussed. This technique may be applicable to other metallurgical batch processes in which large columns of high-temperature off-gases containing $\mathrm{CO}, \mathrm{CO}_{2}$, and particles are present.
\end{abstract}

DOI: $10.1007 / \mathrm{s} 11663-008-9211-1$

(C) The Minerals, Metals \& Materials Society and ASM International 2009

\section{INTRODUCTION}

DURING the decarburization phase of the basic oxygen furnace (BOF) process, oxygen is blown into the molten steel bath to reduce its carbon content from approximately 4 pct to $<0.1$ pct. $^{[1]}$ As a consequence, a column of mostly carbon monoxide $(\mathrm{CO})$ and some carbon dioxide $\left(\mathrm{CO}_{2}\right)$ emerges from the mouth of the converter. If the exhaust hood operates at slightly negative pressure, room air will be entrained by the offgas above the mouth, and a flame will form as air and hot CO mix. The high-temperature off-gas entrains solid particles rich in iron oxides and other components from the slag layer, such as $\mathrm{CaO}, \mathrm{SiO}_{2}, \mathrm{FeO}, \mathrm{P}_{2} \mathrm{O}_{5}, \mathrm{Al}_{2} \mathrm{O}_{3}$, $\mathrm{MnO}$, and $\mathrm{MgO} .^{[1]}$

Measuring the off-gas temperature in real time at the mouth of a BOF converter presents both challenges and benefits. The harsh environment (high temperatures and particle loadings, with constant vibration) precludes the long-term use of thermocouples. Other approaches, such as the application of midinfrared tunable diode lasers ${ }^{[2]}$ or $\mathrm{CO}_{2}$ thermometers, ${ }^{[3]}$ are still in the technology demonstration stage. The reliability of laser solutions, which require that the laser beam travel across the offgas column, is hindered by particle scattering and

SALVADOR REGO-BARCENA and REBECCA SAARI, Graduate Students, REZA MANI, Postgraduate Student, FUT YANG, Student, and MURRAY J. THOMSON, Professor, are with the Department of Mechanical and Industrial Engineering, University of Toronto, Toronto, ON, Canada. Contact e-mail: thomson@mie. utoronto.ca

Manuscript submitted December 3, 2007.

Article published online February 4, 2009. sudden gas temperature differences. Based on the available literature ${ }^{[3,4]}$ commercial $\mathrm{CO}_{2}$ thermometers rely on a narrow-band model of $\mathrm{CO}_{2}$ approximately $4.5 \mu \mathrm{m}$ at high temperatures $(>873 \mathrm{~K})$. These thermometers have been used to measure exhaust gas temperatures of approximately $973 \mathrm{~K}$ in an incinerator. However, the principle of operation of these thermometers is not clearly stated and, to the best of our knowledge, they have not yet been successfully applied in steelmaking furnaces. The current proof-of-concept test at a full-scale BOF shows the potential of a recent emission spectroscopy technique ${ }^{[5]}$ to measure gas temperature and particle emissivity in real time.

The benefits of having real-time temperature data are twofold: (1) computational fluid dynamic (CFD) models of the exhaust-handling system for a $\mathrm{BOF}^{[6]}$ usually resort to estimating off-gas temperature for their boundary condition and (2) dynamic temperature data, combined with off-gas concentration, would allow mass and energy balances around the converter that may serve as the basis for a model-based feedback-control strategy. This approach is currently being developed for an electric arc furnace ${ }^{[7]}$ with the gas temperature and concentration at the fourth hole; the same principle may readily be applied to a $\mathrm{BOF}$.

Particle emissivity $\left(\varepsilon_{p}\right)$ is a useful variable in CFD codes that include radiation heat-transfer submodels for calculating the radiative source term in the energy conservation equation for fluid flow. For simplicity, while CFD codes normally work with spectrally averaged particle emissivities, ${ }^{[8]}$ the present technique yields spectral emissivity at $3.95 \mu \mathrm{m}$. However, for coal ash samples containing $\mathrm{Fe}_{2} \mathrm{O}_{3}, \mathrm{MgO}, \mathrm{CaO}, \mathrm{SiO}_{2}$, and $\mathrm{SO}_{3}$, and for single-component samples of $\mathrm{FeO}$ and $\mathrm{Fe}_{2} \mathrm{O}_{3}$, 
Bohnes et al. ${ }^{[9]}$ showed that the spectrally averaged particle emissivity and the emissivity at $3.95 \mu \mathrm{m}$ are very similar for temperatures above $1200 \mathrm{~K}$. All these components are also common to BOF particles. ${ }^{[1,10]}$ The emissivity values of Bohnes et al. and Linka et al..$^{[1]}$ were taken from a layer of particles in a crucible, to characterize coal ash deposits on heat-transfer surfaces. Thus, they cannot be applied to individual particles entrained in a gas stream. One of the strengths of the current technique is that it measures $\varepsilon_{p}$ for particles suspended in a high-temperature gas column. The emissivity measured by Bohnes et al. and Linka et al. is normally referred to as directional emissivity ${ }^{[12]}$ or effective emissivity $\left(\varepsilon_{\mathrm{eff}}\right){ }^{[5]}$ as in the present study, whereas the individual emissivity $\left(\varepsilon_{p}\right)$ is simply called particle emissivity. Both are spectral quantities. The analytical relationship between $\varepsilon_{\text {eff }}$ and $\varepsilon_{p}$ for semiinfinite particle clouds has been developed by RegoBarcena et al. ${ }^{[5]}$

A brief review of the methodology for the retrieval of off-gas temperature and particle emissivity is followed by a description of the experimental setup and the measuring campaign at a full-scale BOF. In the discussion, the temperature and emissivity values are analyzed; they are compared to the relevant literature and provide an estimate of the experimental uncertainty.

\section{METHODOLOGY}

\section{A. Temperature and Particle Emissivity Retrieval}

The radiation that arrives at the infrared sensor is emitted from the region directly above the mouth of the converter (Section III). At this location, the flame sheet that results from the mixing of $\mathrm{CO}$ and atmospheric air is only starting to form and is neglected. In this way, the radiation source is modeled as a homogeneous column of $\mathrm{CO}$ and $\mathrm{CO}_{2}$ with small particles. It has been shown ${ }^{[5]}$ that from the profile of the radiance $v s$ the wavelength between 3.8 and $5.0 \mu \mathrm{m}$, two separate regions may be distinguished for large gas columns with $\mathrm{CO}, \mathrm{CO}_{2}$, and particles. The range 3.80 to $4.10 \mu \mathrm{m}$ is characterized by particle-only emission that will appear nonblack if the particles are assumed to be gray in that wavelength window. Between 4.56 and $4.70 \mu \mathrm{m}$, the radiance that arrives at the sensor is a mixture of gas and particle emissions. In this region, for long path lengths (e.g., several meters), the radiation is normally saturated, i.e., it follows a blackbody (BB) curve described by Planck's distribution in

$$
B_{\lambda}(T)=\frac{C_{1}}{\lambda^{5}\left[\exp \left(C_{2} / \lambda T\right)-1\right]}
$$

where $\lambda$ is the wavelength of the radiation and the first and second radiation constants are $C_{1}=1.191 \times 10^{-16}$ $\mathrm{W} \cdot \mathrm{m}^{2} \cdot \mathrm{sr}^{-1}$ and $C_{2}=14,388 \mu \mathrm{m} \cdot \mathrm{K}$, respectively. ${ }^{[13]}$ Because Planck's distribution is a function only of temperature and wavelength, by fitting the measured intensity profiles in those two wavelength regions to a $\mathrm{BB}$ profile with temperature as the independent variable, two temperature values may be retrieved: ${ }^{[5]}$ (1) from the gas-particle region, if the condition for saturation is met, the temperature will be some average of the physical temperature of the off-gas $\left(T_{g+p}\right)$; and (2) from the particle region, a lower temperature $\left(T_{p}\right)$ will be measured if the particle emissivity between 3.8 and $4.1 \mu \mathrm{m}$ is less than unity. (This temperature is called a brightness temperature, to differentiate it from the physical temperature). Figure 1 illustrates all of these concepts for the conditions at the decarburization phase of a typical heat from the industrial test: an off-gas column diameter of $2.87 \mathrm{~m}$, with a 90 pet $\mathrm{CO}+10$ pet $\mathrm{CO}_{2}$ (by volume) gas mixture at $1500 \mathrm{~K}$ and a constant particle emissivity of 0.45 between 3.8 and $4.1 \mu \mathrm{m}$. This scenario is modeled with RADCAL, a one-dimensional solver of the radiative transfer equation (RTE) that accounts for the absorption and emission of gases and particles but neglects particle scattering. ${ }^{[14]}$ The drop in radiance of approximately $4.25 \mu \mathrm{m}$ is due to absorption by a $4-\mathrm{m}$ air layer at ambient temperature $(313 \mathrm{~K})$ between the offgas column and the instrument containing approximately $300 \mathrm{ppm} \mathrm{CO}_{2}$. The data from the so-called atmospheric $\mathrm{CO}_{2}$ region (atm. $\mathrm{CO}_{2}$ in Figure 1) are disregarded in the analysis.

The particle emissivity at $3.95 \mu \mathrm{m}$ is calculated from the asymptotic solution of the RTE for semi-infinite gasparticle columns; this solution depends on the cosine of the emerging angle of the emitted radiation relative to the normal direction $\mu$ (Figure 3(a)) and the particle emissivity itself (Eq. [2]).

$$
\varepsilon_{\mathrm{eff}, p}(\mu)=\frac{1+2 \mu}{\left[1+2 \mu \sqrt{\varepsilon_{p}}\right]} \cdot \sqrt{\varepsilon_{p}}
$$

The effective emissivity of the particle region $\left(\varepsilon_{\mathrm{eff}, p}\right)$ is calculated from the retrieved particle brightness temperature and the temperature of the off-gas, ${ }^{[5]}$ as expressed in

$$
\varepsilon_{\mathrm{eff}, p}=\frac{B_{3.95 \mu \mathrm{m}}\left(T_{p}\right)}{B_{3.95 \mu \mathrm{m}}\left(T_{g+p}\right)}
$$

where $B_{\lambda}(T)$ is Planck's distribution in Eq. [1].

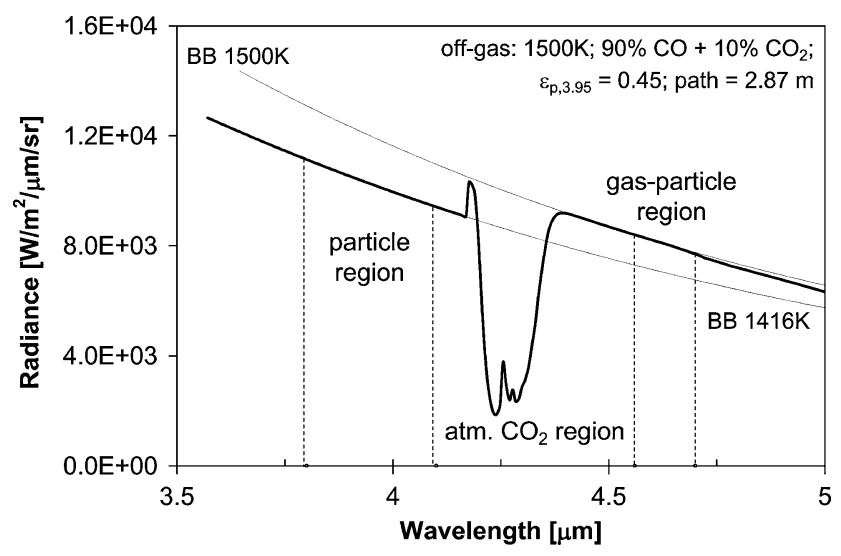

Fig. 1-Simulation of the emitted radiance profile using RADCAL, for typical values of the off-gas in the middle of a typical heat. 
The assumption of saturation in the gas-particle region, even for large path lengths, needs to be assessed, because particle scattering may lower the otherwise BB radiation from $\mathrm{CO}$ and $\mathrm{CO}_{2}$ between 4.56 and $4.70 \mu \mathrm{m} .{ }^{[15]}$ If particle-scattering effects reduce significantly ( $>5 \mathrm{pct}$ ) the BB profile between 4.56 and $4.70 \mu \mathrm{m}$, Rego-Barcena and Thomson ${ }^{[15]}$ provide an iterative procedure to account for particle scattering. Particlescattering effects are assessed from the initial estimate of particle emissivity and from the $\chi$ parameter:

$$
\chi=\frac{\kappa_{g}}{N_{p} A_{p}}
$$

which is a ratio of the gas mixture absorption coefficient $\left(\kappa_{g}\right)$ to the particle extinction coefficient; the latter is the product of the particle cross-sectional area $\left(A_{p}\right)$, assumed uniform, and the particle number density in the gas column $\left(N_{p}\right)$. For $\chi<1$ and $\varepsilon_{p}<0.5$, it is advisable to correct for particle effects. Thus, estimating $\chi$ is an essential step toward determining the uncertainty in the measurement of $\varepsilon_{p}$ and $T_{g+p}$. The assumptions that led to the calculation of $\chi$ for the conditions at the industrial site are presented next.

\section{B. Calculating $\chi$ to Validate Assumption of Saturation in Gas-Particle Region}

The parameter $\chi$ is calculated with Eq. [4], using estimates of $\kappa_{g}, N_{p}$, and $A_{p}$. The gas mixture absorption coefficient $\kappa_{g}$ at $4.60 \mu \mathrm{m}$ was determined from the model of the Laboratoire d'Energétique Moléculaire et Macroscopique, Combustion (EM2C) of the Centre National de la Recherche Scientifique (Châtenay-Malabry Cedex, France) and the École Centrale Paris (Paris, France), based on the statistical narrow-band method by Malkmus. ${ }^{[16]}$ Table I summarizes the simulations for several temperatures and compositions. Because the offgas at the mouth of the converter is assumed to contain a mixture of $\mathrm{CO}$ and $\mathrm{CO}_{2}$, the values used to calculate $\chi$ are those in the furthest right column in Table I.

Particles from the BOF may be divided into coarse dust and fine dust. ${ }^{[17]}$ Coarse dust, accounting for roughly one-third of the total dust by weight, ${ }^{[18]}$ has a diameter of between 20 and $1000 \mu \mathrm{m}$, with approximately 80 pct (cumulative frequency) of all particle diameters smaller than $500 \mu \mathrm{m}$ and 50 pct below roughly $200 \mu \mathrm{m} .{ }^{[17]}$ The other two-thirds consist of fine dust. Some researchers ${ }^{[17]}$ reported that $80 \mathrm{wt}$ pct of fine particles displayed diameters less than $100 \mu \mathrm{m}$ and that $50 \mathrm{wt}$ pet were particles with diameters below $30 \mu \mathrm{m}$. However, another study ${ }^{[18]}$ showed that the average

Table I. Absorption Coefficient $\kappa_{g}\left(\mathrm{~m}^{-1}\right)$ at $4.60 \mu \mathrm{m}$ for 2.87-m Gas Column at Several Compositions (Volume Percent) and Temperatures from the EM2C Model $^{[16]}$

\begin{tabular}{cccc}
$T(\mathrm{~K})$ & 100 Pct CO & $100 \mathrm{Pct} \mathrm{CO}_{2}$ & $90 \mathrm{Pct} \mathrm{CO}+10 \mathrm{Pct} \mathrm{CO}_{2}$ \\
\hline 1300 & 0.93 & 7.39 & 2.15 \\
1500 & 0.84 & 12.01 & 2.96 \\
1700 & 0.77 & 16.91 & 3.85 \\
1900 & 0.72 & 21.55 & 4.69 \\
\hline
\end{tabular}

particle size should be smaller, and claimed that $91 \mathrm{pct}$ (cumulative frequency) of fines had diameters less than $2.5 \mu \mathrm{m}$. Ray et al., ${ }^{[19]}$ who did not comment on the presence of coarse particles, reported a diameter range of between 0.5 and $15 \mu \mathrm{m}$ for a BOF without postcombustion (as is the case with the converter of this study). In the present work, the analysis of the particle effects (Section V-D) will be carried out with the values from the lower estimates of the particle diameter as a worst-case scenario. The reason is that, for the same mass of particles, it is the smallest size that would have the largest effect on the temperature and particle emissivity retrieved by the infrared sensor. ${ }^{[15]}$ Therefore, because Ray et al. found that $89 \mathrm{wt}$ pet of all particles had a diameter between 1 and $10 \mu \mathrm{m}, 5 \mu \mathrm{m}$ is taken here as an average.

The particle shape is assumed to be spherical, based on scanning electron microscope images, ${ }^{[10,19]}$ so that $A_{p}=\pi r_{p}^{2}$, where $r_{p}$ is the mean particle radius. The average particle number density $N_{p}$ for each heat is estimated from the total particle mass and cumulative off-gas volume. The available process variables from the industrial test were the estimated steel weight at tap and the cumulative oxygen consumption. The total mass of particles $\left(m_{p}\right)$ was approximated as 1.8 pct of the tapped steel. ${ }^{[17,18]}$ The number of particles $\left(n_{p}\right)$, then, is simply the total particle volume divided by the volume of one particle:

$$
n_{p} \approx \frac{\left(\frac{m_{p}}{\rho_{p}}\right)}{\left(\frac{4 \pi}{3} r_{p}^{3}\right)}
$$

where $\rho_{p}$ is the particle density $\left(\approx 5400 \mathrm{~kg} / \mathrm{m}^{3}\right.$, which is an average for the fine and coarse dust from the $\left.\operatorname{data}^{[17]}\right)$.

The off-gas volume was estimated from the oxygen consumption from a simple overall mole balance around the BOF, which assumes that the reaction products are 90 pet $\mathrm{CO}$ and 10 pet $\mathrm{CO}_{2}$, according to Reaction [6]. This ratio of $\mathrm{CO}$ to $\mathrm{CO}_{2}$ is normally used to model the decarburization period. ${ }^{[17]}$ In Reaction [6], all coefficients have been normalized by the $\mathrm{O}_{2}$ coefficient, to show the relationship between the number of off-gas moles produced from the reaction of one mole of $\mathrm{O}_{2}$ consumed.

$$
\begin{aligned}
\mathrm{O}_{2(\mathrm{~g}, \text { lance })}+1.82 \mathrm{C}_{(\text {bath })} \rightarrow & 0.18 \mathrm{CO}_{2(\mathrm{~g}, \text { off-gas })} \\
& +1.64 \mathrm{CO}_{(\mathrm{g}, \text { off-gas })}
\end{aligned}
$$

Thus, for each cubic meter of $\mathrm{O}_{2}$, there are $1.82 \mathrm{~m}^{3}$ of off-gas produced. Because the cumulative oxygen consumption for each heat is reported at $1 \mathrm{~atm}$ and $289 \mathrm{~K}$, the relationship between the oxygen and off gas volumes becomes

$$
V_{\text {off-gas }, 289 \mathrm{~K}} \approx 1.82 V_{\mathrm{O}_{2}, 289 \mathrm{~K}}
$$

This is the same relationship that Chigwedu et al. ${ }^{[17]}$ used in their modeling of the off-gas evolved for a converter assuming a 90 pet $\mathrm{CO}+10$ pet $\mathrm{CO}_{2}$ mixture. 
The high temperature of the off-gas at the mouth of the converter is taken into account by correcting its volume from $289 \mathrm{~K}$ to $T_{g+p}$ (the off-gas temperature, for example, $1500 \mathrm{~K}$ ) using the ideal gas law:

$$
V_{\text {off }- \text { gas }, T_{g+p}}=V_{\mathrm{O}_{2}, 289 \mathrm{~K}} \frac{T_{g+p}}{289 \mathrm{~K}}
$$

Finally, $N_{p}$ is just the ratio of the total number of particles to the off-gas volume:

$$
N_{p}=\frac{n_{p}}{V_{\text {off-gas }, T_{g+p}}}
$$

The ranges of $\chi$ for each heat appear in Section $\mathrm{V}-\mathrm{D}$.

\section{EXPERIMENTAL}

The infrared sensor prototype was assembled with off-the-shelf parts. As seen in Figure 2, the prototype consists of three main components: standard lightcollection optics, a grating spectrometer, and a lineararray pyroelectric detector. ${ }^{[5]}$ The optical elements in the lens tube are a $2.5-\mathrm{cm}^{\mathrm{CaF}_{2}}$ planoconvex focusing lens (focal distance $=75$ at $588 \mathrm{~nm}$ ) and a long pass filter (3.60 to $6.89 \mu \mathrm{m}$ ). The filter blocks incoming radiance of between 1.85 and $2.5 \mu \mathrm{m}$, whose second order of diffraction would fall into the region of interest. Wavelength calibration was based on transmission experiments with two narrow-band pass filters and yielded an overall wavelength range of 3.52 to $4.78 \mu \mathrm{m}$, as determined immediately prior to the start of the two-day campaign at the industrial site. Radiance calibration was performed with a true BB source (Mikron M330, Mikron Infrared, Inc., Oakland, NJ) and radiance factors were obtained for temperatures between 879 and $1973 \mathrm{~K}$. The data acquisition software was customized to carry out the retrieval algorithms for the temperature and particle emissivity in real time. Each acquisition-retrieval cycle lasts a total of 2.025 seconds.

In order to mount the infrared sensor on the skirt of the BOF, all components were housed in a heat-resistant National Electrical Manufacturers Association (NEMA) box, fitted with a sapphire window (diameter = $7.5 \mathrm{~cm}$ ). The box had an intake for instrument air designed so that the air flowed parallel to the outside window surface, to prevent particle accumulation on the

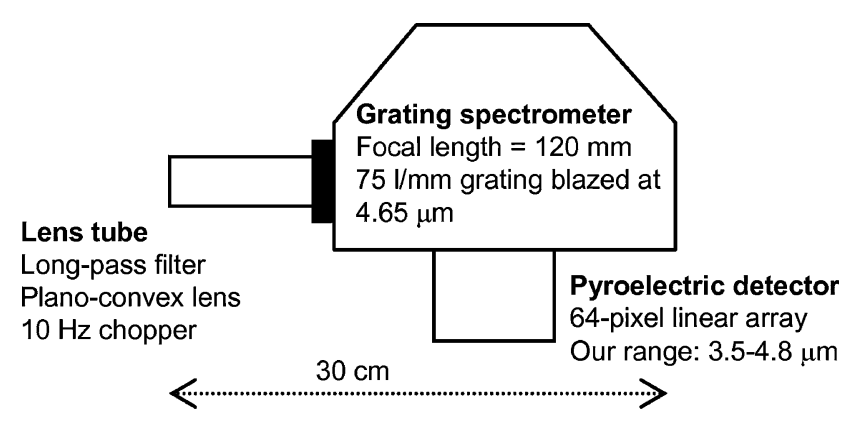

Fig. 2-Main components of the infrared sensor. collection optics. The positive pressure created by the air pressurizing the box kept particles from entering the enclosure. The BOF unit was rated at 168 tonnes. The mouth of the converter had a diameter of $3.04 \mathrm{~m}$. The location of the sensor on the skirt and the view of the inside of the NEMA box are shown in Figures 3(a) and (b), respectively. The vertical distance between the mouth of the converter and the exhaust hood above it was only $0.46 \mathrm{~m}$. The flange that supports the sensor's NEMA box was welded onto the skirt of the furnace. Thus, it was impractical to study vertical variations in temperature and emissivity with the current setup.

The field trials took place over two days and included seven heats. Three heats had aim-carbon levels below 0.08 pct and are referred to as "low-carbon heats." Four had aim-carbon levels above 0.30 pct ("high-carbon heats"). Other properties relevant to these heats appear in Table II.

\section{RESULTS}

Figure 4 shows several sample profiles from the calibrated output of the infrared sensor (radiance $v s$ wavelength), before and after the oxygen lance was stopped. The legend refers to the number of seconds before or after the lance went offline. A qualitative description of this figure may give some insight into the physical processes taking place. In this example, the largest temperature was retrieved from the highest profile (124 seconds before the oxygen flow ceased). The temperature was slightly lower when the lance stopped; it fell considerably afterward, because there was no more oxygen with which to generate the off-gas flowing past the infrared sensor.

Following the methodology of Rego-Barcena et al., ${ }^{[5]}$ the off-gas temperature and particle emissivity at $3.95 \mu \mathrm{m}$ were retrieved in real time during a campaign at a 168-tonne BOF converter that spanned seven heats, as shown in Figure 5. The start of the heat is taken as the moment the oxygen lance went online. The vertical discontinued line to the furthest right in these plots marks the time at which the oxygen was stopped. The other two lightly dotted vertical lines are the start and end times of the steady-state decarburization period (as defined here), from which the average off-gas temperature and particle-emissivity values are reported in Table III. As explained in Section V-D, the analysis for the particle effects based on the estimated $\chi$ and the initial (retrieved) value of $\varepsilon_{p}$ provided an estimate of the uncertainty in $T_{g+p}$ and $\varepsilon_{p}$.

The average temperature and particle emissivity from the decarburization period of all the heats were calculated while trying to avoid the more pronounced oscillations (the vertical lines in Figure 5 for the start and end times of the so-called steady-state period of each heat). Within these subsets, it was observed that the number of emissivity outliers, i.e., the values of $\varepsilon_{p}$ larger than 1 , became noticeable in heats 6 and 7 . The air pressure into the box that housed the infrared sensor was increased from 5 to 20 psig before heat 6 . Because the number of emissivity outliers grew at that point, the magnitude of the 


\section{TOP VIEW OF FURNACE}

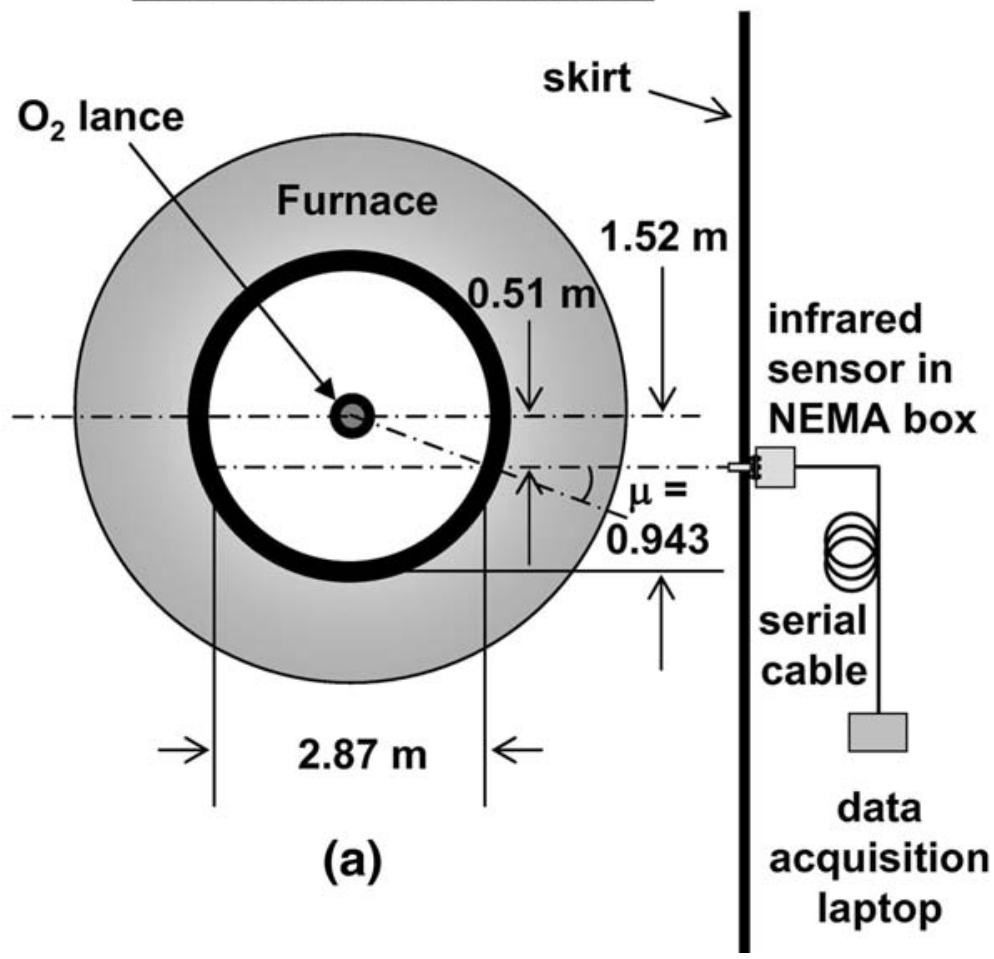

\section{IR SENSOR IN NEMA BOX}

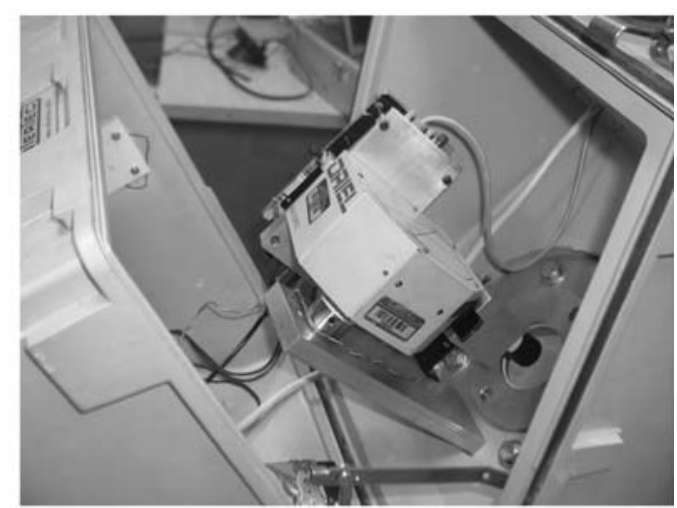

Fig. 3-(a) Schematic of the location of the infrared sensor on the BOF skirt and (b) a view of the NEMA box with the infrared sensor inside. The white box is the grating spectrometer and the metal flange on the side attaches the pyroelectric detector to the outlet of the spectrometer (Fig. 2 ).

Table II. Bath Properties from Seven Heats of Field Trials

\begin{tabular}{lccc}
\hline $\begin{array}{l}\text { Heat } \\
\text { Number }\end{array}$ & $\begin{array}{c}\text { Aim Carbon } \\
\text { (Wt Pct) }\end{array}$ & $\begin{array}{c}\text { TD1* Carbon } \\
\text { (Wt Pct) }\end{array}$ & $\begin{array}{c}\text { TD1* Bath } \\
\text { Temperature (K) }\end{array}$ \\
\hline 1 & $>0.30$ & 0.055 & 1964 \\
2 & $>0.30$ & 0.058 & 1940 \\
3 & $<0.08$ & 0.037 & 1999 \\
4 & $<0.08$ & 0.040 & 1979 \\
5 & $<0.08$ & 0.035 & 1942 \\
6 & $>0.30$ & 0.078 & 1990 \\
7 & $>0.30$ & 0.170 & 1978 \\
\hline
\end{tabular}

$* \mathrm{TD} 1=$ value at first turndown.

temperature and emissivity data for heats 6 and 7 are likely suspect. To remove the effect of the outlier points, especially for heats 6 and 7 , new average values of $T_{g+p}$ and $\varepsilon_{p}$ were calculated without the outlier points. This resulted in a negligible change in $T_{g+p}(<1 \mathrm{pct})$, but a significant 10 pct decrease in $\varepsilon_{p}$, for heats 6 and 7 . Table III contains the number of data points in the steady-state zone of each heat, the average $T_{g+p}$ and $\varepsilon_{p}$ with all data and without the outliers, the number of emissivity outliers, and the percent decrease in $\varepsilon_{p}$.

By concentrating on heats 1 through 5, two groups of particle-emissivity data emerge: high-carbon heats (1 and 2) and low-carbon heats (3 through 5). As shown in Table III, the emissivity data for these two groups are significantly different and will be addressed in Section $\mathrm{V}-\mathrm{B}$.

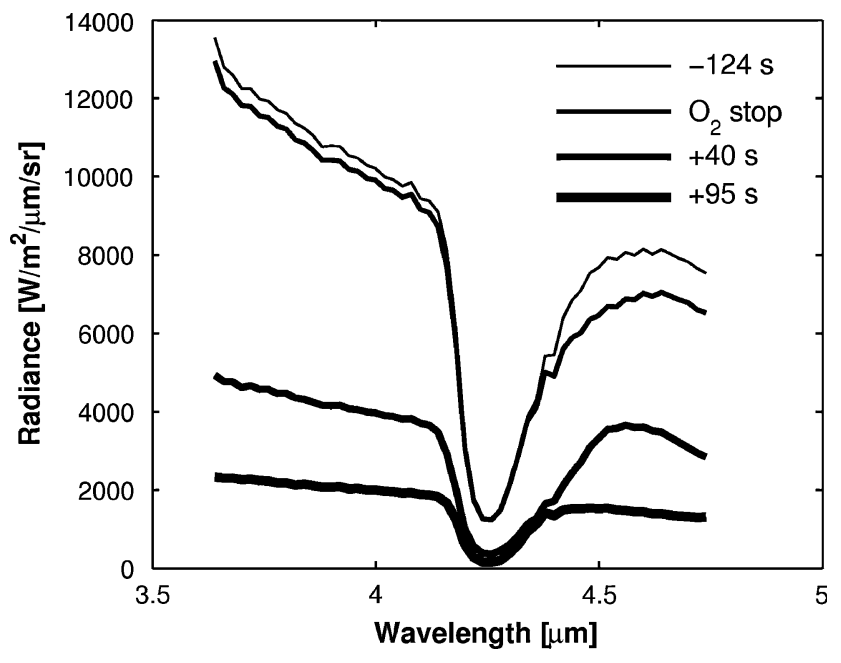

Fig. 4-Sample calibrated profiles from the output of the infrared sensor before and after the oxygen lance was stopped (heat 7).

\section{DISCUSSION}

This section is structured around the two physical properties in the off-gas that were measured $\left(T_{g+p}\right.$ and $\varepsilon_{p}$ ) and the validation of the assumptions in the retrieval algorithms. It also includes an estimate of the experimental uncertainty in $T_{g+p}$ and $\varepsilon_{p}$, after accounting for particle-scattering effects. 
Heat 1

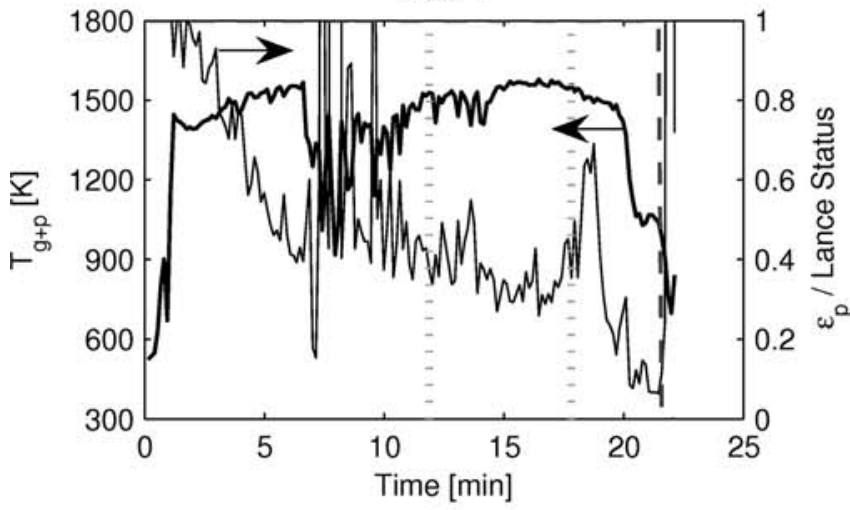

Heat 3
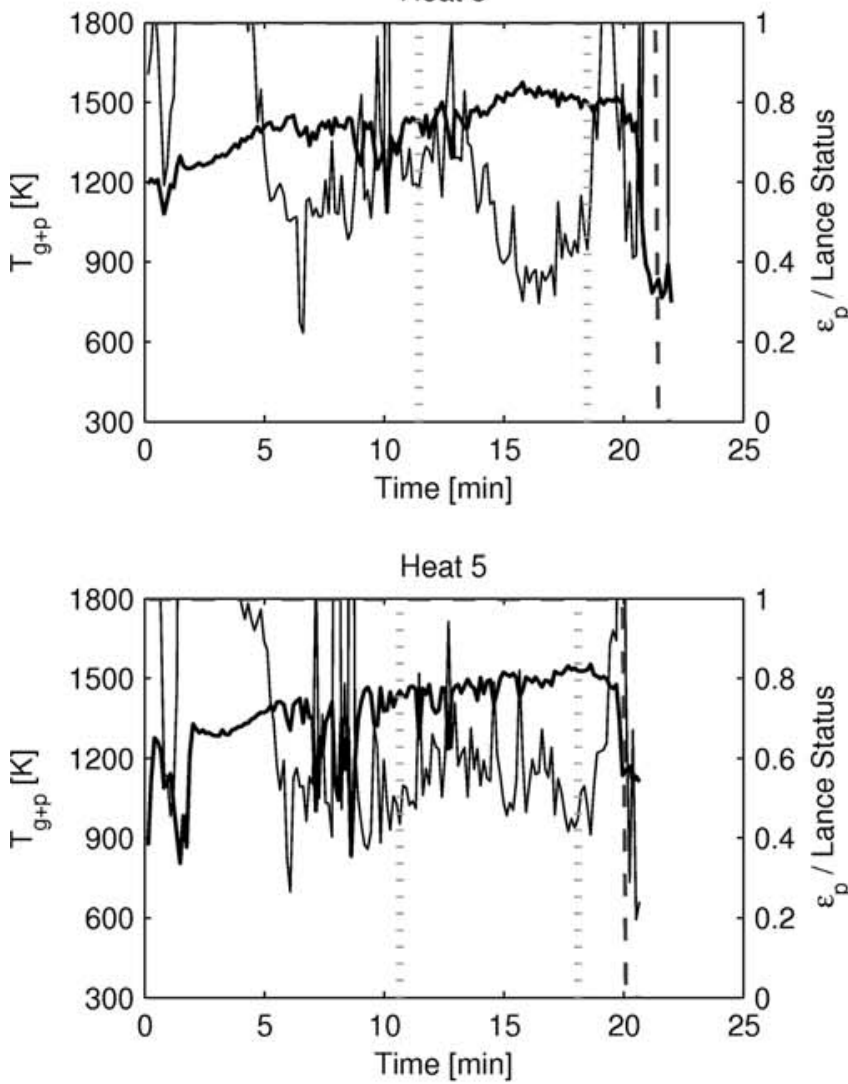

Heat 7

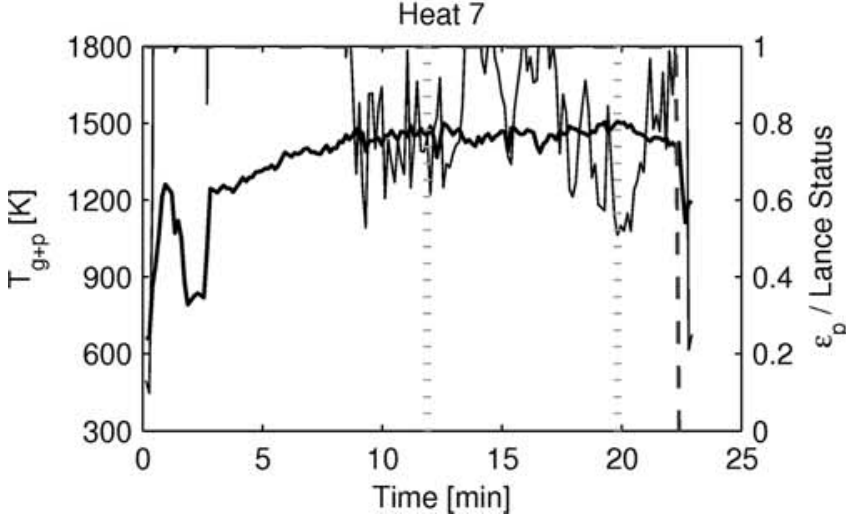

Heat 2
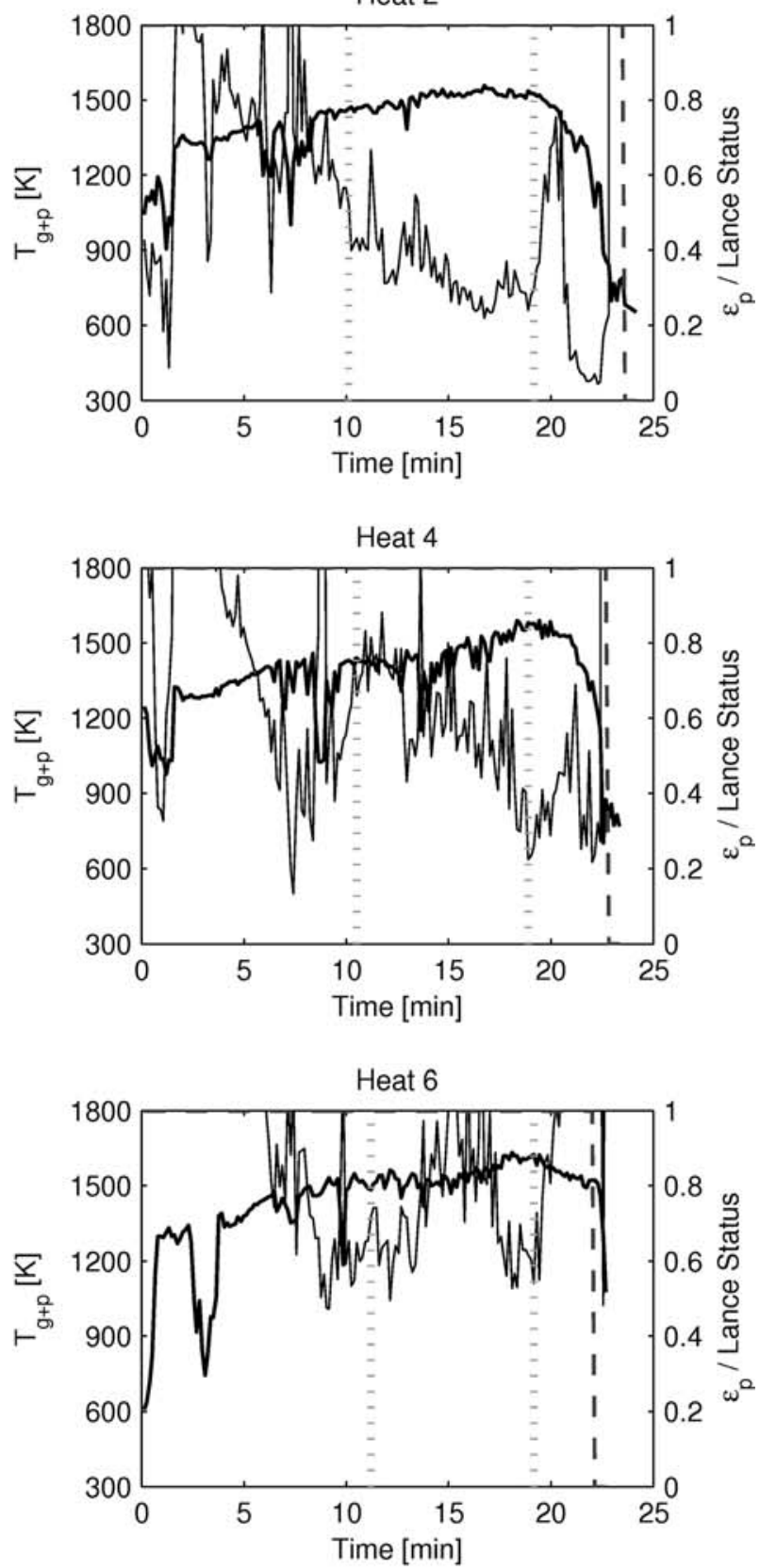

Fig. 5-Off-gas temperature $\left(T_{g+p}\right)$ and particle emissivity $\left(\varepsilon_{p}\right)$ retrieved by the infrared sensor for the seven heats during the oxygen-blowing period. The data are reported as a moving average every four measurement intervals $(8.1 \mathrm{~s})$. 
Table III. Data for Steady-State Decarburization Zone of All Heats

\begin{tabular}{|c|c|c|c|c|c|c|c|c|c|}
\hline $\begin{array}{l}\text { Heat } \\
\text { Number }\end{array}$ & $\begin{array}{l}\text { Aim } \\
\text { Carbon }\end{array}$ & $\begin{array}{l}\text { Data } \\
\text { Points }\end{array}$ & $\begin{array}{c}\text { Average } \\
\varepsilon_{p}\end{array}$ & $\begin{array}{l}\text { Average } \\
T_{g+p}(\mathrm{~K})\end{array}$ & $\begin{array}{c}\text { Outlier } \\
\text { Fraction (Pct) }\end{array}$ & $\begin{array}{l}\text { New Data } \\
\text { Points }\end{array}$ & $\begin{array}{c}\text { New } \\
\text { Average } \varepsilon_{p}\end{array}$ & $\begin{array}{c}\text { New Average } \\
T_{g+p}(\mathrm{~K})\end{array}$ & $\begin{array}{c}\text { Fractional } \\
\text { Decrease in } \varepsilon_{p}(\mathrm{Pct})\end{array}$ \\
\hline 1 & high* & 178 & 0.368 & 1527 & 0.0 & 178 & 0.368 & 1527 & 0.0 \\
\hline 2 & high & 268 & 0.346 & 1506 & 0.0 & 268 & 0.346 & 1506 & 0.0 \\
\hline 3 & low** & 208 & 0.528 & 1488 & 1.4 & 205 & 0.518 & 1491 & 1.9 \\
\hline 4 & low & 250 & 0.604 & 1446 & 2.4 & 244 & 0.589 & 1450 & 2.5 \\
\hline 5 & low & 221 & 0.569 & 1469 & 1.8 & 217 & 0.557 & 1473 & 2.2 \\
\hline 6 & high & 238 & 0.764 & 1546 & 13.5 & 206 & 0.692 & 1554 & 9.4 \\
\hline 7 & high & 237 & 0.842 & 1456 & 20.7 & 188 & 0.758 & 1466 & 10.1 \\
\hline
\end{tabular}

*High: aim carbon $>0.3 \mathrm{wt}$ pct.

** Low: aim carbon $<0.08$ wt pct.

\section{A. Analysis of Off-Gas Temperature Data}

The temperature trace captures well the refining phase in a BOF: soon after the oxygen lance goes online, $\mathrm{CO}$ and $\mathrm{CO}_{2}$ are evolved from the liquid bath and flow upward past the mouth of the converter where the infrared sensor is located. The sensor records a steep initial change in the off-gas temperature (e.g., heats 1 and 6, Figure 5). In some cases (e.g., heats 3 and 4), there was a sudden rise in temperature before the oxygen lance came online; this is likely from the evolution of warm room air mixed with $\mathrm{CO}_{2}$-containing combustion gases from the hot metal charge. Toward the end of the heat, the off-gas temperature drops, either because no more oxygen is being supplied (heats 6 and 7, Figure 5) or because the carbon content in the bath is very low (heats 1 through 5). The end result is the same in both scenarios: the evolution of $\mathrm{CO}$ stops and there is no more hightemperature radiation arriving at the infrared sensor, whether from gases or from particles entrained by the gas. As a general comparison, the temperatures retrieved from the tunable diode laser by Allendorf et al. ${ }^{[2]}$ from a pilot-scale converter ( 1 tonne, $0.36-\mathrm{m}$ mouth diameter) and a full-scale converter (300 tonnes, 3.65-m mouth diameter) were 1450 and $1800 \mathrm{~K}$, respectively. The laser sensor was positioned over the mouth of both converters, as in the present case. Because a laser beam would travel through the full path length of the gas-particle mixture, it is logical to expect higher temperatures from this technique, as compared to the passive infrared sensor, in which temperatures and emissivities are weighed toward the outer (and, thus, slightly cooler) side of the gas column. ${ }^{[5]}$ In this regard, it would be sensible to expect the pilot-scale converter temperatures from the laser technique ${ }^{[2]}$ to be close to the current measurements, as is the case. Additional evidence for this hypothesis is provided by comparing the passive infrared sensor temperatures with the initial results from a passive $\mathrm{CO}_{2}$ thermometer (Land Instruments CD1, Land Instruments International, Limited, Leicester, Leicestershire, UK) shown in Figure 6. The $\mathrm{CO}_{2}$ thermometer was positioned to look directly at the mouth of the same converter as the infrared sensor, but measurements were taken weeks after the present campaign. ${ }^{[20]}$ Because the conditions of the two heats are likely different, Figure 6 does not provide a direct validation of the current temperature technique. However, Figure 6 does suggest that the temperature from the infrared sensor is reasonable.

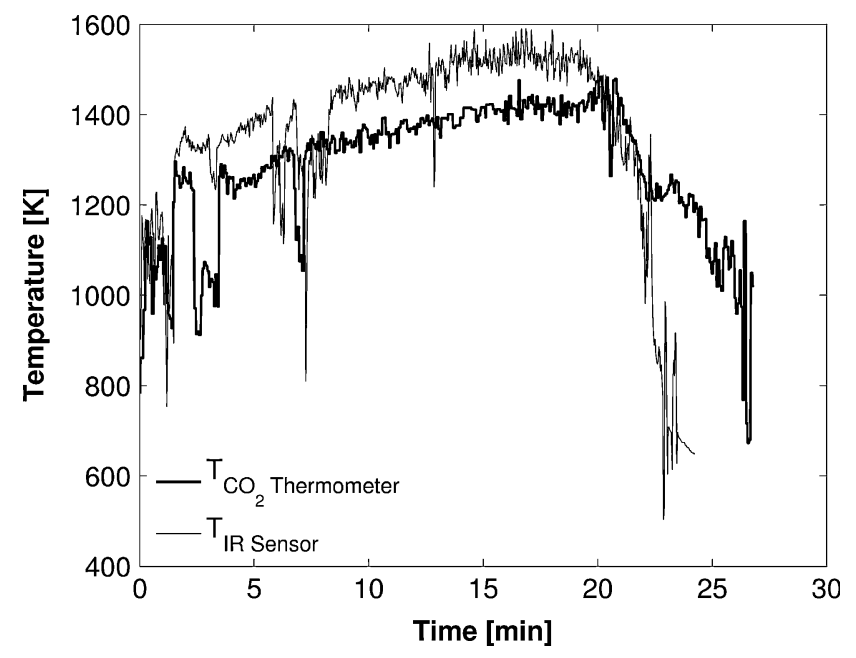

Fig. 6 - Comparison between off-gas temperature data at the mouth of the same converter from a $\mathrm{CO}_{2}$ thermometer (Land Instruments, CD1) and the infrared sensor (heat 2). Data were taken weeks apart.

Another comparison could be made with Nedar, ${ }^{[10]}$ who installed a probe $27 \mathrm{~m}$ above the mouth of the converter, in a study on particle formation in a BOF. The gas temperature in the middle of the heat (7 through 15 minutes) is quoted as being between 1073 and $1273 \mathrm{~K}$. A decrease of 300 to $400 \mathrm{~K}$ in the off-gas temperature between the mouth and the position at which particles were collected would seem plausible.

One of the direct applications of the off-gas temperature data is useful for CFD modelers who would otherwise have to assume an off-gas temperature as a boundary condition for their simulations. For example, in the design of a secondary exhaust hood for a BOF, ${ }^{[6]}$ modelers could have used the present technique to measure the off-gas temperature at the mouth of the converter, to characterize the fumes that needed to be captured by the new exhaust hood.

\section{B. Analysis of Particle Emissivity Data}

The BOF particles at the mouth of the converter are a mixture of iron oxides and other flux agents. Once the metal-slag emulsion is formed (6 to 7 minutes from the onset of blowing), the main mechanism of the solid 
particle formation is the ejection of metal and slag. ${ }^{[10]}$ From the analysis of 27 heats in a BOF converter, Nedar ${ }^{[10]}$ found that particles were mostly spherical and consisted either of a layer of iron oxide surrounding a solid core of metallic iron or a porous sphere made of oxidized iron or slag components. The main elements present were $\mathrm{Fe}, \mathrm{Ca}, \mathrm{Mg}$, and $\mathrm{Mn}$. The current technique yields an average particle emissivity that lumps together the contributions of all components, thus simplifying the task of the CFD modeler.

Linka et al. ${ }^{[11]}$ and Bohnes et al. ${ }^{[9]}$ measured spectral effective emissivity from a particle layer of oxides and lignite ash samples with a spectral radiometer in the laboratory. Table IV summarizes their findings and the present data for high- and low-carbon heats (heats 1 through 5 in Table III), for comparison. Note that effective emissivity ${ }^{[5]}$ applies to a cloud or layer of particles; this best describes the measurements against which the present data are compared. ${ }^{[9,11]}$ The effective emissivity is itself a function of the individual particle emissivity (Eq. [2]), which is the variable of interest in this study. The effective emissivity of a layer of particles is greater than the particle emissivity, because of the inscattering of radiation that adds to the emission of the particles themselves. ${ }^{[5]}$ It is important to keep in mind that it is the particle emissivity that should be used in a CFD model to describe the radiative properties of particles entrained by a gas. On the other hand, the effective emissivity should be used to characterize the radiative emission emerging from a particle layer as, for example, the emitted radiance from an ash deposit on a heat-exchanger surface. In the case of the off-gas of a BOF, the effective emissivity characterizes the radiance, leaving a layer of gas and particles, and is thus an output of the RTE.

It is interesting that the single-phase components tend to have lower emissivities than the multicomponent samples with a high iron oxide content. For example, the emissivity of lignite ash 3 , which had the most $\mathrm{Fe}_{2} \mathrm{O}_{3}$ of the three (24.7 wt pct), was higher than the emissivity of the single $\mathrm{Fe}_{2} \mathrm{O}_{3}$ sample. Because iron (III) oxide has a strong effect on particle emissivity between 1 and $5 \mu \mathrm{m}$, due to the strong absorption band of $\mathrm{Fe}^{2+}$ of approximately $1 \mu \mathrm{m},{ }^{[21]}$ the present BOF particles likely have a higher $\mathrm{Fe}_{2} \mathrm{O}_{3}$ content than the single-phase and coal ash samples in Bohnes et al..$^{[9]}$ Instead of having to estimate the average $\varepsilon_{p}$ from the most abundant singlephase components, the current technique demonstrates a convenient way to measure in situ the average particle emissivity for off-gas systems. This aggregated approach seems more accurate, given the differences that may exist between single-phase components and mixtures of components.

It was stated earlier (Table III) that a quantitative difference in $\varepsilon_{p}$ exists between low- and high-carbon heats. The average particle emissivity for lowcarbon heats ( 2 through 5 ) was 0.55 , while for highcarbon heats ( 1 and 2$)$, it was 0.36 . The slightly higher average temperature for high-carbon heats $(1517 \mathrm{~K}$ for high carbon, $1471 \mathrm{~K}$ for low carbon) likely does not account for the whole difference. Figure 7 shows a linear fit of the particle emissivity $v s$ temperature for heats 1 through 5 . There is a clear decrease in emissivity with temperature, which was also observed in a coal-fired boiler. ${ }^{[5]}$ However, there remains an apparent distinction between the emissivity of low- and high-carbon heats, judging from the vertical location of the lines in Figure 7.

The discrepancy may lie in the different recipes and oxygen lance practices for each type of heat. A possible explanation may lie in the quantity of additives (burnt lime and dolomite) and the ratio of the estimated steel weight at tap over $\mathrm{O}_{2}$ consumption (Table V). Other factors, such as the initial carbon content of the bath and the quantity of limestone added, were reported by the plant to be the same for all five heats.

Table V shows that high-carbon heats (1 and 2) had more burnt lime $(\mathrm{CaO})$ added and a slightly lower steel$\mathrm{O}_{2}$ ratio. The amount of dolomite $(59 \mathrm{wt}$ pet $\mathrm{CaO}, 39 \mathrm{wt}$ pet $\mathrm{MgO}$, and 2 wt pet $\mathrm{SiO}_{2}$ ) was very similar, although

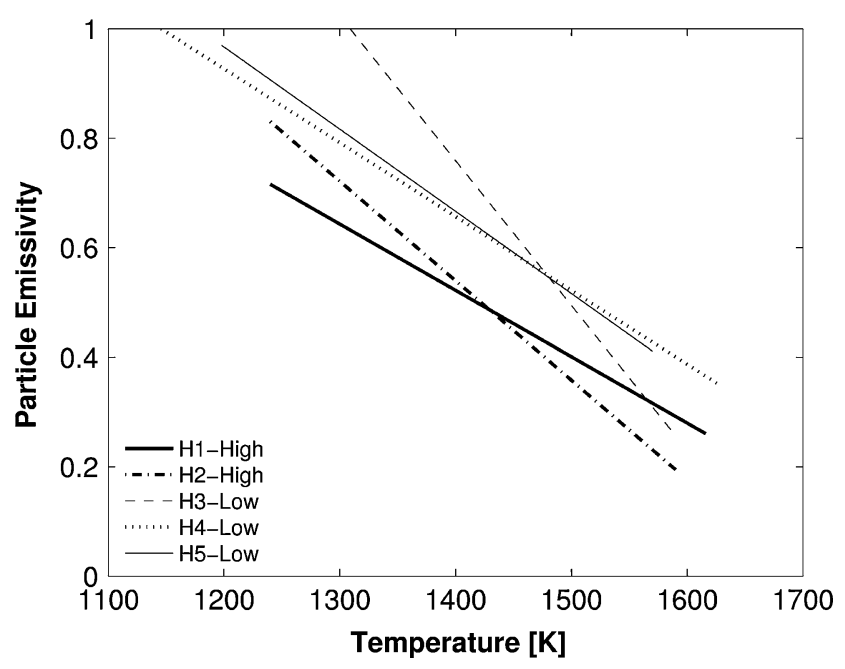

Fig. 7-Linear fits of particle emissivity vs temperature for heats 1 through 5 .

Table IV. Comparison of $\varepsilon_{\text {eff }}$ at $3.95 \mu \mathrm{m}$ and Similar Temperatures for Relevant Oxides ${ }^{[9,11]}$ and Present Results

\begin{tabular}{|c|c|c|c|c|c|c|c|c|c|}
\hline $\mathrm{FeO}^{*}$ & $\mathrm{Fe}_{2} \mathrm{O}_{3} *$ & $\mathrm{CaO}^{*}$ & $\mathrm{SiO}_{2} * *$ & $\mathrm{MgO}^{* *}$ & Lignite Ash 1* & Lignite Ash 2* & Lignite Ash $3^{*}$ & Low Carbon*** & High Carbon*** \\
\hline 0.76 & 0.59 & 0.72 & 0.60 & 0.59 & 0.62 & 0.48 & 0.81 & 0.90 & 0.82 \\
\hline
\end{tabular}


Table V. Additives and Estimated Mass of Steel at Tap per $\mathrm{O}_{2}$ Consumption, for Heats 1 through 5

\begin{tabular}{llccc}
\hline Heat & $\begin{array}{c}\text { Aim } \\
\text { Carbon }\end{array}$ & $\begin{array}{c}\text { Burnt } \\
\text { Lime }(\mathrm{kg})\end{array}$ & $\begin{array}{c}\text { Dolomite } \\
(\mathrm{kg})\end{array}$ & $\begin{array}{c}\mathrm{Steel} / \mathrm{O}_{2} \\
\left(\mathrm{~kg} / \mathrm{Nm}^{3}\right)\end{array}$ \\
\hline 1 & high* & 5815 & 4200 & 17.10 \\
2 & high & 8265 & 5679 & 16.27 \\
3 & low** & 3098 & 4087 & 17.76 \\
4 & low & 3198 & 4096 & 17.69 \\
5 & low & 3134 & 4101 & 19.05 \\
\hline
\end{tabular}

*High: aim carbon $>0.3 \mathrm{wt}$ pct.

** Low: aim carbon $<0.08 \mathrm{wt}$ pct

heat 2 had approximately 30 pct more and recorded the lowest emissivity. Because the emissivity of $\mathrm{MgO}$ is among the lowest in Table IV, it could be that this component is playing a more pronounced role in the overall particle emissivity. However, the cause of the observed difference in $\varepsilon_{p}$ between low- and high-carbon heats is not fully understood at present and remains to be explored in future tests.

While CFD codes normally work with spectrally averaged emissivities $\varepsilon_{\text {tot }}$ (Eq. [10]) to save on computational time, the present technique yields a single spectral emissivity value at $3.95 \mu \mathrm{m}$. However, the $\varepsilon_{p}$ at $3.95 \mu \mathrm{m}$ for coal-ash samples agrees closely with the total particle emissivity between 1 and $15 \mu \mathrm{m},{ }^{[9]}$ which is a suitable range within which to calculate $\varepsilon_{\text {tot }}$, because it accounts for 98 pct of the $\mathrm{BB}$ radiance at $1500 \mathrm{~K}$. The major species of the coal samples in that study were $\mathrm{Fe}_{2} \mathrm{O}_{3}$, $\mathrm{MgO}, \mathrm{CaO}, \mathrm{SiO}_{2}$, and $\mathrm{SO}_{3}$ (wt pet $>5.0$ ), the first four of which are also common in BOF particles: ${ }^{[1,10]}$

$$
\varepsilon_{\text {tot }}(T)=\frac{\int_{\lambda_{1}}^{\lambda_{2}} \varepsilon_{p, \lambda}(T) B_{\lambda}(T) d \lambda}{\int_{\lambda_{1}}^{\lambda_{2}} B_{\lambda}(T) d \lambda}
$$

Most important, however, is that the data in Bohnes et al. ${ }^{[9]}$ show that the relationship $\varepsilon_{\text {tot }} \approx \varepsilon_{3.95 \mu \mathrm{m}}$ applies to particle layers of the single-phase $\mathrm{FeO}$ and $\mathrm{Fe}_{2} \mathrm{O}_{3}$, which are the main components in BOF particles. For example, at $1473 \mathrm{~K}, \varepsilon_{3.95 \mu \mathrm{m}}=0.76(\mathrm{FeO})$ and 0.69 $\left(\mathrm{Fe}_{2} \mathrm{O}_{3}\right)$, whereas $\varepsilon_{\text {tot }}=0.73(\mathrm{FeO})$ and $0.68\left(\mathrm{Fe}_{2} \mathrm{O}_{3}\right)$. Therefore, it is proposed that the data in the present study can be used as the total emissivity required by radiation submodels in the $\mathrm{CFD}$ codes.

\section{Assumptions in Retrieval Algorithms}

One of the fundamental assumptions of this technique is that the radiation in the 4.56 to $4.7 \mu \mathrm{m}$ range is saturated (i.e., BB radiation). This is easily achievable with enough $\mathrm{CO}_{2}$ in the gas mixture, given a sizeable path length for the gas column (for example, $3 \mathrm{~m}$ ). It was assumed that the off-gas at the mouth of the converter was 90 pct $\mathrm{CO}+10$ pct $\mathrm{CO}_{2}$ by volume, for which Figure 1 shows that the emitted radiance from the off-gas in the gas-particle wavelength region matches very well the $\mathrm{BB}$ line at the same temperature. The question then arises as to what is the minimum $\mathrm{CO}_{2}$ concentration before the emitted radiance starts

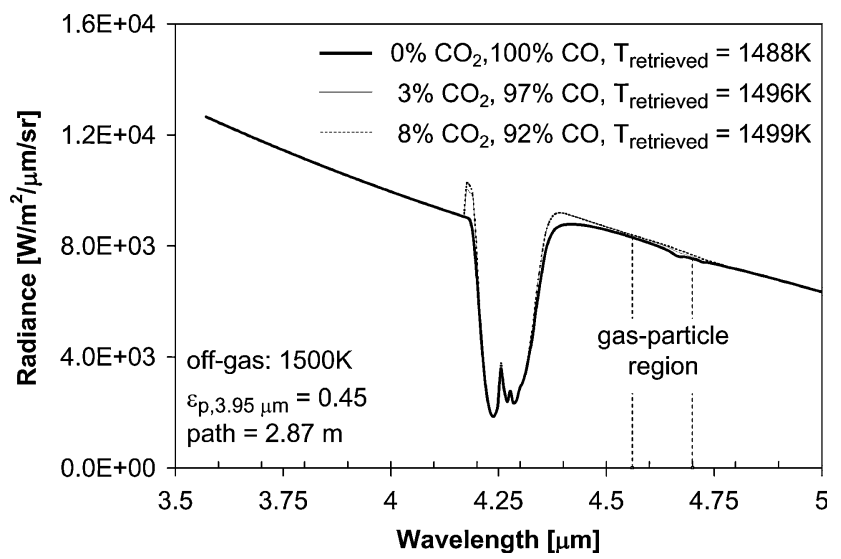

Fig. 8-Simulated radiance profiles for different levels of $\mathrm{CO}_{2}$ in the off-gas using RADCAL; the retrieved temperature from the gasparticle region (4.56 to $4.7 \mu \mathrm{m})$.

deviating from saturation conditions. Figure 8 addresses this point with modeled radiance profiles for 0,3 , and 8 vol pet $\mathrm{CO}_{2}$ (balance $=\mathrm{CO}$ ), all of them at $1500 \mathrm{~K}$ and $1 \mathrm{~atm}$, with the $\varepsilon_{p}$ set to 0.45 . The temperatures that would have been retrieved from the gas-particle region appear on the legend of the figure. They are $0.5 \mathrm{pct}$ lower at worst $\left(0\right.$ pet $\mathrm{CO}_{2}+100$ pet $\mathrm{CO}$ scenario). A similar calculation at lower temperatures showed that, from the simulated profile for 100 pct $\mathrm{CO}$ at $900 \mathrm{~K}$, the retrieved temperature would have been $897 \mathrm{~K}$. The reason for the robustness of the temperature-retrieval method is the use of absolute radiances in the leastsquares minimization algorithm, as opposed to the actual shape or slope of the radiance profile. ${ }^{[5]}$ (This discussion assumes that particle-scattering effects may be neglected, when in reality they did introduce some uncertainty in $T_{g+p}$ and $\varepsilon_{p}$ (Section V-D).)

Finally, one of the assumptions in the asymptotic solution to the $\mathrm{RTE}^{[12]}$ is that the particle size parameter $X>10$, when the porosity of the medium is less than 50 pct, where $X=2 \pi r_{p} / \lambda$ and the porosity is $\left(1-f_{v}\right)$ pct. From the assumption of $r_{p \text {,avg }}=2.5 \mu \mathrm{m}, X$ varies between 4.0 and 3.4 for $\lambda=3.95$ and $4.65 \mu \mathrm{m}$, respectively. However, the porosity of the medium (as explained in Section V-D) is greater than 99.99 pct, meaning that particles are so far apart that coherent effects are unlikely and the emission by particles is isotropic. ${ }^{[22]}$

\section{Particle-Scattering Effects and Uncertainty Analysis}

The scattering of radiance (assumed isotropic) by particles is inversely related to their emissivity, i.e., the lower $\varepsilon_{p}$, the more light will be scattered. In this case, the absolute radiance that arrives at the infrared sensor would be lower, resulting in lower values of the retrieved temperature from the gas-particle region that measures 4.56 to $4.7 \mu \mathrm{m}$, which at that point is no longer the physical temperature of the off-gas but the brightness temperature for that wavelength region. ${ }^{[15]}$ The criterion for correcting temperature and particle-emissivity data to account for particle effects is based on $\chi$ and the original value of $\varepsilon_{p}$. As a general rule, if $\chi>1$ and 
Table VI. Variables Used in Calculation of $\chi$ at $r_{p}=2.5$ and $5 \mu \mathrm{m}$, to Check for Particle-Scattering Effects on $T_{g+p}$ and $\varepsilon_{p}$

\begin{tabular}{|c|c|c|c|c|c|c|c|c|c|}
\hline $\begin{array}{l}\text { Heat } \\
\text { Number }\end{array}$ & $\begin{array}{c}\text { Expected } \\
\text { Steel Weight } \\
\text { at Tap (kg) }\end{array}$ & $\begin{array}{c}V_{\mathrm{O}_{2}, 289 \mathrm{~K}} \\
\left(\mathrm{~m}^{3}\right)\end{array}$ & $\begin{array}{c}V_{p} \\
\left(\mathrm{~m}^{3}\right)\end{array}$ & $\begin{array}{c}V_{\text {off-gas at }} \text { at } \\
1500 \mathrm{~K} \\
\left(\mathrm{~m}^{3}\right)\end{array}$ & $f_{v}$ & $\begin{array}{c}N_{p}\left(\mathrm{~m}^{3}\right) \\
\text { for } \\
r_{p}=2.5 \mu \mathrm{m}\end{array}$ & $\begin{array}{c}N_{p} A_{p}\left(\mathrm{~m}^{-1}\right) \\
\text { for } \\
r_{p}=2.5 \mu \mathrm{m}\end{array}$ & $\begin{aligned} \chi= & \kappa_{g} / N_{p} A_{p} \\
& \text { for } \\
r_{p}= & 2.5 \mu \mathrm{m}\end{aligned}$ & $\begin{array}{c}\chi=\kappa_{g} / N_{p} A_{p} \\
\quad \text { for } \\
r_{p}=5 \mu \mathrm{m}\end{array}$ \\
\hline 1 & 138,027 & 8070 & 0.460 & 76,314 & $6.0 \times 10^{-6}$ & $9.21 \times 10^{10}$ & 1.81 & 1.64 & 3.27 \\
\hline 2 & 137,690 & 8464 & 0.459 & 80,036 & $5.7 \times 10^{-6}$ & $8.76 \times 10^{10}$ & 1.72 & 1.72 & 3.44 \\
\hline 3 & 142,134 & 8005 & 0.474 & 75,698 & $6.3 \times 10^{-6}$ & $9.56 \times 10^{10}$ & 1.88 & 1.58 & 3.15 \\
\hline 4 & 141,191 & 7980 & 0.471 & 75,457 & $6.2 \times 10^{-6}$ & $9.53 \times 10^{10}$ & 1.87 & 1.58 & 3.16 \\
\hline 5 & 142,511 & 7481 & 0.475 & 70,745 & $6.7 \times 10^{-6}$ & $1.03 \times 10^{11}$ & 2.01 & 1.47 & 2.94 \\
\hline 6 & 140,616 & 7852 & 0.469 & 74,252 & $6.3 \times 10^{-6}$ & $9.64 \times 10^{10}$ & 1.89 & 1.56 & 3.13 \\
\hline 7 & 140,124 & 7374 & 0.467 & 69,727 & $6.7 \times 10^{-6}$ & $1.02 \times 10^{11}$ & 2.01 & 1.47 & 2.95 \\
\hline
\end{tabular}

$\varepsilon_{p}>0.5$, particle-scattering effects may be neglected. ${ }^{[15]}$ However, even if $\chi \approx 2$, for $\varepsilon_{p}<0.5$, it is worth checking the influence of the particle scattering on the saturated profile of the gas-particle region, as demonstrated here. Section II-B outlined the procedure for estimating $\chi$ based on the available process variables for the BOF test. Table VI summarizes the process variables that served as inputs, which, together with the assumptions in Section II-B, permitted the determination of $\chi$ for each heat. The gas-absorption coefficient $\kappa_{g}=2.96 \mathrm{~m}^{-1}$ was taken from Table I for 90 pet $\mathrm{CO}+10$ pet $\mathrm{CO}_{2}$ (by volume) at $1500 \mathrm{~K}$. The average particle radius was varied between 2.5 and $5 \mu \mathrm{m}$, because the smallest radius is the worst-case scenario used in this study, and $5 \mu \mathrm{m}$ represents 89 pct of all particles in Ray et al. ${ }^{[19]}$

The iterative procedure for adjusting $\varepsilon_{p}$ and $T_{g+p}$ has been outlined elsewhere. ${ }^{[15]}$ The worst-case scenario $\left(r_{p}=2.5 \mu \mathrm{m}\right.$, lowest $\chi$ ) for both low- and high-carbon heats in Table III was found in heat 1 (high-carbon, $\chi=1.64$ ) and heat 5 (low-carbon, $\chi=1.47$ ). The average $\varepsilon_{p}$ for the steady-state zone was 0.368 (heat 1) and 0.557 (heat 5). Similarly, the retrieved temperatures from the gas-particle region were $1527 \mathrm{~K}$ for heat 1 and $1473 \mathrm{~K}$ for heat 5 (Table III). The corrected values of $\varepsilon_{p}$ decreased to $0.286(-22.3$ pct, heat 1) and 0.447 ( -19.8 pct, heat 5$)$, while the new values of the off-gas temperature increased to $1564 \mathrm{~K}(+2.4 \mathrm{pct}$, heat 1$)$ and $1500 \mathrm{~K}(+1.8 \mathrm{pct}$, heat 5$)$. For the average $r_{p}=5 \mu \mathrm{m}$, the changes are more modest. After taking particlescattering effects into account, particle emissivities were $0.324(-12.0$ pct, heat 1$)$ and $0.499(-10.4$ pct, heat 5), while the off-gas temperatures rose to $1546 \mathrm{~K}(1.24 \mathrm{pct}$, heat 1) and $1486 \mathrm{~K}$ (0.88 pct, heat 5). Thus, the uncertainty in the retrieved variables, which hinges on the assumption of an average $r_{p}$ for BOF particles, is at most -22 pet for $\varepsilon_{p}$ and +2.4 pct for $T_{g+p}$. Low- and high-carbon heats display similar uncertainties, which decreased by approximately 50 pct when the assumed particle radius doubled to $5 \mu \mathrm{m}$. Because normally the particle size distribution at an industrial furnace is not measured in real time, from which one may determine an average $r_{p}$, the nominal maximum uncertainty of the infrared sensor for an $\varepsilon_{p}$ of approximately 0.4 is $-20 \mathrm{pct}$; for temperatures at approximately $1500 \mathrm{~K}$, it is +2 pct. This uncertainty should be born in mind when considering the data in Table III and Figure 5.

A smaller source of uncertainty in the retrieved variables stems from the radiance-calibration procedure.
To estimate it, the retrieved and actual temperatures from the radiation of a BB source, IR-563 (Boston Electronics Corporation, Brookline, MA), which was different from the one used for radiance calibration (Mikron M330, Mikron Infrared, Inc., Oakland, NJ (Section III)), were compared. The mean error was 0.2 pct between 663 and $1323 \mathrm{~K}$, which is well within the 1 pct temperature uncertainty of the IR-563 source. As expected, the discrepancy between the retrieved temperature from the particle-only and gas-particle spectral regions for the IR-563 BB spectra was very small ( 0.4 pct).

\section{CONCLUSIONS}

This article summarizes the successful implementation of a novel infrared sensor in a steelmaking furnace for measuring gas temperature $\left(T_{g+p}\right)$ and spectral particle emissivity $\left(\varepsilon_{p}\right)$ based on midinfrared-emission spectroscopy. The major conclusions from the study are as follows.

1. Real-time (every 2 seconds) profiles of $T_{g+p}$ and $\varepsilon_{p}$ signals were presented for all the heats, and average values from the decarburization zone were calculated (Table III).

2. The estimated uncertainty in the measurements was dominated by particle-scattering effects and was, at worst, 2 pct in $T_{g+p}$ at approximately $1500 \mathrm{~K}$ and 20 pct in $\varepsilon_{p}$ between 0.2 and 0.8 . Other sources of uncertainty in $T_{g+p}$ were the radiance-calibration procedure $(0.2 \mathrm{pct})$ and the assumption of $10 \mathrm{vol}$ pct $\mathrm{CO}_{2}$ in the off-gas column $(0.5 \mathrm{pct})$.

3. Off-gas temperatures from the present study compare favorably with those from published in-situ tests with a tunable-diode laser and a $\mathrm{CO}_{2}$ thermometer.

4. Previous studies measured the emissivity from a layer of particles and could not provide an average individual particle emissivity that may be used in CFD codes to model radiation from particles in a gas. This observation renders the current particle-emissivity technique unique. More in-situ tests would be necessary to achieve representative values for a specific converter.

5. The decreasing trend between $\varepsilon_{p}$ and temperature agrees well with trends observed in a coal-fired boiler with the same infrared sensor.

6. The average emissivity from the decarburization phase of low-carbon heats was noticeably higher than 
that of high-carbon heats $(0.55$ and 0.36 , respectively); although temperature plays a role, this difference is not fully understood at present.

7. This technique may be applicable to other metallurgical batch processes that meet the following criteria: the presence of a high-temperature gas stream $(T>1000 \mathrm{~K})$ that entrains dust particles with an average diameter greater than $5 \mu \mathrm{m}$ and with enough $\mathrm{CO} / \mathrm{CO}_{2}$ and path length (for example, a 2-m off-gas column with 10 vol pet $\mathrm{CO}_{2}$ or a mixture of $\mathrm{CO} /$ $\mathrm{CO}_{2}$ ). These conditions may apply to electric arc furnaces, cement kilns, and coal-fired boilers.

8. Real-time off-gas temperature and particle-emissivity data will likely be useful to CFD modelers for setting temperature-boundary conditions and to processcontrol professionals who would like to perform continuous energy balances around the furnace.

\section{ACKNOWLEDGMENTS}

The authors gratefully acknowledge the support of the Ontario Centres of Excellence, Sustainable Development Technology Canada and Tenova Goodfellow, Inc. The authors also express special gratitude to Bernie Goldberg and Mohamed Boutazakhti from Tenova Goodfellow, for their assistance with the industrial tests.

\section{NOMENCLATURE}

$A_{p} \quad$ particle cross-sectional area $\left(\mathrm{m}^{2}\right)$

$B$ Planck's radiance distribution for a $\mathrm{BB}(\mathrm{W} /$ $\mathrm{m}^{2} / \mu \mathrm{m} / \mathrm{sr}$ )

$C_{1}, C_{2} \quad$ first and second radiation constants (Eq. [1])

$f_{v} \quad$ particle volume fraction $(-)$

$m_{p} \quad$ particle mass in one heat $(\mathrm{kg})$

$N_{p} \quad$ particle number density in one heat $\left(1 / \mathrm{m}^{3}\right)$

$n_{p} \quad$ number of particles in one heat $(-)$

$r_{p} \quad$ particle radius $(\mu \mathrm{m})$

$T_{g+p} \quad$ off-gas temperature $(\mathrm{K})$

$T_{p} \quad$ brightness temperature from the particle wavelength region (Figure 1) (K)

$V_{\text {off-gas }}$ total off-gas volume produced in one heat $\left(\mathrm{m}^{3}\right)$

$V_{\mathrm{O}_{2}} \quad$ total lance oxygen volume consumed in one heat $\left(\mathrm{m}^{3}\right)$

$V_{p} \quad$ total volume of particles in one heat $\left(\mathrm{m}^{3}\right)$

$X \quad \equiv 2 \pi r_{p} / \lambda$, particle size parameter $(-)$

\section{GREEK SYMBOLS}

$\chi \quad \equiv \kappa_{p} / N_{p} A_{p}$, parameter used to estimate particle effects (Section $\mathrm{V}-\mathrm{D})(-)$

$\varepsilon_{\text {eff }}$ effective emissivity of a single- or doublecomponent medium (spectral) $(-)$ $\varepsilon_{p} \quad$ particle emissivity at $3.95 \mu \mathrm{m}$ (spectral) $(-)$

$\varepsilon_{\text {tot }}$ total particle emissivity (Eq. [10]) (-)

$\kappa_{p} \quad$ spectral gas-absorption coefficient $\left(\mathrm{m}^{-1}\right)$

$\lambda \quad$ wavelength $(\mu \mathrm{m})$

$\mu \quad$ cosine of the emerging angle of the emitted radiation relative to the normal (Eq. [2]) (-)

\section{SUBSCRIPTS}

$g+p \quad$ off-gas property (containing gases and particles)

$p \quad$ particle-only property, evaluated at the midpoint of the particle wavelength region $(3.8$ to $4.1 \mu \mathrm{m})$

\section{REFERENCES}

1. G. Béranger, G. Henry, and G. Sanz: The Book of Steel, 1st ed., Intercept Limited, Andover, United Kingdom, 1996, pp. 116163.

2. S.W. Allendorf, D.K. Ottesen, D.R. Hardesty, D. Goldstein, C.W. Smith, and A.P. Malcolmson: Iron Steel Eng., 1998, vol. 75, pp. 31-35.

3. For Temperature Measurement in Waste Incinerators, Land Infrared, Land Instruments International, Incinerator Thermometer CD1, Bristol, PA, 2000.

4. T.G. Baynon: AIP Conf. Proc. 684, American Institute of Physics, Melville, NY, 2003, vol. 7, pp. 819-24.

5. S. Rego-Barcena, R. Saari, R. Mani, S. El-Batroukh, and M.J. Thomson: Meas. Sci. Technol., 2007, vol. 18, pp. 3479-88.

6. T. Plikas, J. Woloshyn, and D. Johnson: AISTech-Iron and Steel Technology Conf. Proc., vol. 1, Association for Iron and Steel Technology, Indianapolis, IN, 2007, pp. 745-56.

7. J. Maiolo, M. Boutazakhti, C.W. Li, and C. Williams: AISTechIron and Steel Technology Conf. Proc., vol. 1, Association for Iron and Steel Technology, Indianapolis, IN, 2007, pp. 673-89.

8. E.H. Chui, P.M.J. Hughes, and G.D. Raithby: Combust. Sci. Technol., 1993, vol. 92, pp. 225-42.

9. S. Bohnes, V. Scherer, S. Linka, M. Neuroth, and H. Brüggermann: Proc. ASME Summer Heat Transfer Conf., HT2005-72099, American Society of Mechanical Engineers, New York, NY, 2005, pp. $175-82$.

10. L. Nedar: Steel Res., 1996, vol. 67, pp. 320-26.

11. S. Linka, S. Wirtz, and V. Scherer: Proc. ASME Summer Heat Transfer Conf., HT2003-47187, 2003, pp 33-39.

12. B. Hapke: Theory of Reflectance and Emittance Spectroscopy, 1st ed., Cambridge University Press, New York, NY, 1993, pp. 36572.

13. M.F. Modest: Radiative Heat Transfer, 2nd ed., Academic Press, San Diego, CA, 2003, pp. 7-8.

14. W.L. Grosshandler: NIST Tech. Note 1402, 1993.

15. S. Rego-Barcena and M.J. Thomson: J. Quant. Spectrosc., 2008, vol. 109, pp. 1325-34

16. A. Soufiani and J. Taine: Int. J. Heat Mass Transfer, 1997, vol. 40, pp. 987-91.

17. C. Chigwedu, J. Kempken, A. Ploch, and W. Pluschkell: Steel Res., 1995, vol. 66, pp. 341-48.

18. AP-42: Compilation of Air Pollutant Emission Factors, Vol. 1: Stationary Point and Area Sources, 5th ed., U.S. Environmental Protection Agency, Office of Air Quality Planning and Standards, Research Triangle Park, NC, 1995, sect. 12.5.

19. S.K. Ray, G. Chattopadhyay, and A.K. Ray: J. Air Waste Manage. Assoc., 1997, vol. 47, pp. 716-21.

20. M. Boutazakhti: Tenova Goodfellow, Inc., Mississauga, ON, Canada, personal communication, 2007.

21. S.P. Bhattacharya, T.F. Wall, and M. Arduini-Schuster: Chem. Eng. Process., 1997, vol. 36, pp. 423-32.

22. B. Hapke: University of Pittsburgh, Pittsburgh, PA, personal communication, 2007. 